\title{
OJS OPEN

\section{GEOGRAFIA E EDUCAÇÃO SOCIOAMBIENTAL: PRÁTICAS E EXPERIÊNCIAS COM ALUNOS DO ENSINO BÁSICO EM CATALÃO (GO)}

\author{
Leonoura Katarina Santos ${ }^{1}$, Robério Francisco de Macêdo ${ }^{2}$, Cláudio José Bertazzo ${ }^{3}$
}

\footnotetext{
${ }^{1}$ Mestranda no Programa de Pós-Graduação em Geografia da Universidade Federal de Catalão (UFCat). E-mail: leonourakatarina@ hotmail.com; ORCID: https://orcid.org/0000-0001-5871-7491

2 Graduando em Licenciatura em Geografia na Universidade Federal de Catalão (UFCat). E-mail: roberiomaced@outlook.com; ORCID: https://orcid.org/0000-0002-8994-3763

${ }^{3}$ Professor Dr. em Geografia no Instituto de Geografia da Universidade Federal de Catalão (UFCat). E-mail: cbertazzo@gmail.com; ORCID: https://orcid.org/0000-0002-2973-5540
}

Artigo recebido em 13/04/2021 e aceito em 24/06/2021

\begin{abstract}
RESUMO: O artigo descreve intervenções e uma sequência didática de educação socioambiental com enfoque privilegiados aos princípios agroecológicos. O artigo objetiva demonstrar iniciativas de intervenções de Educação Socioambiental e Agroecológica e destacar sua relevância para a formação dos alunos da Educação Básica - Etapa do Ensino Fundamental. Na metodologia de ensino das aulas utilizou-se perspectivas lúdicas, baseadas em jogos, práticas de segregação de resíduos e, num ambiente gamificado, um Quiz Agroecológico; finalmente aplicou-se uma enquete com os alunos, induzindo a reflexão sobre a qualidade de vida das pessoas, tal como os conhecimentos internalizados sobre tais temáticas. As situações de ensino foram desenvolvidas na Escola Estadual Instituto de Educação Matilde Margon Vaz na cidade de Catalão (GO), em parceria com o Núcleo de Estudos, Pesquisas e Extensão em Agroecologia (NEPEA); integrando a disciplina de Estágio Supervisionado em Geografia II. Os resultados mostram um aprofundamento do aprendizado e a internalização dos conceitos debatidos nas unidades didáticas. Conclui-se que experiência didática com alternativas e técnicas de ensino focadas no aluno e na sua aprendizagem, levam a colheita de aumento de repertório conceitual sobre temas de Geografia de Natureza, como, para exemplo, a Educação Socioambiental e Agroecológica.
\end{abstract}

Palavras-chave: Ensino de Geografia; Agroecologia; Educação Socioambiental.

\section{GEOGRAPHY AND SOCIAL AND ENVIRONMENTAL EDUCATION: PRACTICES AND EXPERIENCES WITH PRIMARY SCHOOL STUDENTS IN CATALÃO (GO)}

\begin{abstract}
:
The article describes interventions and a didactic sequence of socio-environmental education with a special focus on agroecological principles. The article aims to demonstrate initiatives for SocioEnvironmental and Agroecological Education interventions and highlight their relevance for the training of Basic Education students - Elementary School Stage. In the teaching methodology of the classes,

$\begin{array}{lll}\text { Santos; Macêdo; Bertazzo, } 2021 & \text { ISSN 2594-9616 }\end{array}$
\end{abstract}


playful perspectives were used, based on games, waste segregation practices and, in a gamified environment, an Agroecological Quiz; finally, a survey was carried out with the students, inducing reflection on the quality of life of people, as well as the internalized knowledge on such themes. The teaching situations were developed at the State School of Education Matilde Margon Vaz in the city of Catalão (GO), in partnership with the Center for Studies, Research and Extension in Agroecology (NEPEA); integrating the discipline of Supervised Internship in Geography II. The results show a deepening of learning and the internalization of the concepts discussed in the didactic units. It is concluded that didactic experience with alternatives and teaching techniques focused on the student and his / her learning, lead to the increase of conceptual repertoire on themes of Geography of Nature, such as, for example, Socioenvironmental and Agroecological Education.

Keywords: Geography Teaching; Agroecology; Social and Environmental Education.

\title{
GEOGRAFÍA Y EDUCACIÓN SOCIAL Y AMBIENTAL: PRÁCTICAS Y EXPERIENCIAS CON ESTUDIANTES DE PRIMARIA EN CATALÃO (GO)
}

\begin{abstract}
Resumen:
El artículo describe intervenciones y una secuencia didáctica de educación socio ambiental con especial énfasis en los principios agroecológicos. El artículo tiene como objetivo demostrar iniciativas para intervenciones de Educación Socio ambiental y Agroecológica y resaltar su relevancia para la formación de estudiantes de Educación Básica - Etapa de Escuela Primaria. En la metodología de enseñanza de las clases se utilizaron perspectivas lúdicas, basadas en juegos, prácticas de segregación de residuos y, en un ambiente gamificado, un Quiz Agroecológico; finalmente, se realizó una encuesta con los estudiantes, induciendo la reflexión sobre la calidad de vida de las personas, así como el conocimiento interiorizado sobre dichos temas. Las situaciones de enseñanza se desarrollaron en la Escuela Estatal de Educación Matilde Margon Vaz en la ciudad de Catalão (GO), en alianza con el Centro de Estudios, Investigación y Extensión en Agroecología (NEPEA); integrando la disciplina de Pasantía Supervisada en Geografía II. Los resultados muestran una profundización del aprendizaje y la interiorización de los conceptos discutidos en las unidades didácticas. Se concluye que la experiencia didáctica con alternativas y técnicas de enseñanza enfocadas en el alumno y su aprendizaje, conducen al incremento del repertorio conceptual sobre temas de Geografía de la Naturaleza, como, por ejemplo, Educación Socio ambiental y Agroecológica.
\end{abstract}

Palabras clave: Enseñanza de la geografía; Agroecología; Educación Socioambiental.

\section{INTRODUÇÃO}

Este artigo descreve intervenções de Educação Socioambiental e Agroecológica, em uma parceria do NEPEA - Núcleo de Estudos, Pesquisas e Extensão em Agroecologia, com os estagiários da disciplina de Estágio Supervisionado em Geografia II. Todo o projeto de pesquisa didática, preparação de aulas, oficinas e outras intervenções aconteceram na Escola Estadual Instituto de Educação Matilde Margon Vaz, na cidade de Catalão (GO). As turmas que 
participaram da iniciativa foram os $6^{\circ}$ e $7^{\circ}$ anos da escola, somando-se quatro turmas, como apenas estas turmas no momento da pesquisa estavam à disposição dos estagiários, este foi o critério de escolha para realização das intervenções no Ensino Fundamental II.

Tomando como base a necessidade da busca de novos meios que auxiliem as práticas pedagógicas na Ciência Geográfica, assim como, o desenvolvimento da consciência ambiental na escola juntamente com atitudes sustentáveis pois o mundo está em uma travessia de uma crise ambiental que começa em escalas locais. A presente pesquisa teve como problema a seguinte pergunta: Será que presença da disciplina de Educação Socioambiental no Ensino Básico aportada por recursos dinâmicos, especificamente com os alunos do Ensino Fundamental II do Instituto de Educação Matilde Margon Vaz no Município de Catalão, é capaz de levar aos escolares a construção de uma consciência socioecológica, levando a mudanças casa-escola?

O objetivo do artigo consiste em demonstrar a necessidade e a relevância de Educação Socioambiental e Agroecológica na Educação Básica (EB), pois que tais conhecimentos são unidades temáticas de Geografia de Natureza do EF. E, mais especificamente, o artigo objetiva demonstrar resultados dessa experiência para, num ato metacognitivo, repensar e (re) avaliar a proposta de ensino e as estratégias utilizadas, num processo de ir e vir e aprender com as práticas de docência. A importância desse informe e análises serve para o aprofundar o debate acerca das práticas docentes e a utilização de metodologias centradas em diálogos e no protagonismo dos alunos.

As principais categorias trabalhadas com os alunos do EF e discutidas nesse artigo foram: Educação Socioambiental, Educação Agroecológica, Resíduos Sólidos Domésticos e Agrotóxicos. Nelas estão consubstancias o destino das intervenções e os resultados produzidos, todos narrados nesse artigo. Finalmente, apresenta-se os resultados da pesquisa e considerações finais sobre a experiência de ensino e a relevância da educação socioambiental e agroecológica como conteúdo da Geografia na Educação Básica. Assim, a busca por meios diferenciados de ensino para auxiliar na construção do conhecimento geográfico, que visem estimular a curiosidade e o censo crítico dos alunos. De igual modo, sensibilizando-os para as problemáticas locais-globais, motivando-os e envolvendo-os nas aulas de Geografia, ressaltando a Educação Socioambiental como disciplina prioritária e de forma ímpar, é uma justificativa desta pesquisa. 


\section{EDUCAÇÃO SOCIOAMBIENTAL, AGROTÓXICO E AGROECOLOGIA NO EF}

Historicamente, desde os limiares dos tempos muito antigos, a prática agrícola se faz presente em meio a rotina dos povos, pela própria necessidade de sobrevivência. Todavia, tal prática foi sofrendo, a cada século, modificações, fomentadas pela descoberta e aprimoramentos dos meios tecnológicos e informacionais, as quais se concretizam na evolução de técnicas rudimentares de produção, as formas mais inovadoras de cultivo em larga escala. Contudo, o termo inovador, pode aqui ser contestado, uma vez que, os produtores deixaram o uso ecológico 'naturalizado' da agricultura, e passaram a utilizar nas suas práticas agrícolas fórmulas e produtos químicos que tem se demonstrado nocivos à saúde humana.

Por esta perspectiva, faz-se necessário nas aulas da educação básica a discussão acerca de tais efeitos da agricultura na saúde humana, em parceria com a discussão de Agroecologia e Educação Socioambiental nas redes educacionais, apresentando, debatendo e pesquisando na internet sobre técnicas e experiência sustentáveis de produção agrícola que não dependam umbilicalmente dos agroquímicos. Esta necessidade perpassa a discussão das formas de alimentação com as quais estamos condicionados. A situação está compreendida em um mesmo arcabouço com o princípio de qualidade de vida, pois que, ao se ingerir alimentos com cargas potencialmente tóxicas pela presença de químicos agrícolas, o que representa de risco à saúde coletiva? No mesmo sentido, entende-se que a apropriação desses conhecimentos pelos jovens oportunizará que possam evitar tanta exposição a tais potencialidades de intoxicações, iniciando pelo controle em suas próprias residências.

Tem sido amplamente relatado pelas publicações especializadas, Sociedades Científicas e pelas redes de comunicação a crítica posição do Brasil como produtor de alimentos tendo se tornado o maior consumidor de agrotóxicos, em volume dos produtos pesticidas usados nas unidades de lavouras. Em consequência, se acrescem os impactos à saúde dos trabalhadores, consumidores com um potencial incremento de enfermidades crônicas, já desde a primeira infância (INCA, 2015).

Desde 2008, o Brasil tem alcançado a indesejável marca de maior consumidor de agrotóxicos no ranking mundial (CARNEIRO et al. 2015). Segundo o relatório do Instituto Nacional de Câncer José Alencar Gomes da Silva (INCA, 2015), relata que a comercialização de defensivos agrícolas ascendeu de US\$ 2 bilhões para mais de US\$7 bilhões entre o curto período de 2001 e 2008, sendo que em 2011 a venda desses produtos alcançou cerca de US\$ 
8,5 bilhões. Além disso, no primeiro trimestre de 2012, houve um crescimento de 45,9\% sobre o valor do ano anterior (IEA, 2012). Segundo o Sindicato Nacional da Indústria de Produtos para defesa agrícola - SINDAG, esses valores estão distribuídos na comercialização de inseticidas, herbicidas, fungicidas, acaricidas e outros produtos. De acordo, com o levantamento realizado pelo Instituto de Economia Agrícola (IEA), representando o percentual de 43,5\% em 2011, a soja é a principal receptora dos produtos citados acima. (IEA, 2012).

Segundo o Sindicato Nacional da Indústria de Produtos para defesa agrícola SINDAG, esses valores estão distribuídos na comercialização de inseticidas, herbicidas, fungicidas, acaricidas e outros produtos. De acordo, com o levantamento realizado pelo Instituto de Economia Agrícola (IEA), representando o percentual de 43,5\% em 2011, a soja é a principal receptora dos produtos citados acima. (IEA, 2012). O site Repórter Brasil, informa que:

\begin{abstract}
Mesmo durante a quarentena, o Governo Federal continua a aprovar novos agrotóxicos para serem vendidos no mercado brasileiro. Desde março deste ano foram publicados o registro de 118 novos produtos, sendo 84 destinados para agricultores e 34 para a indústria. No mesmo período, as empresas produtoras de pesticidas solicitaram ao Ministério da Agricultura a liberação de mais 216 produtos, que estão sendo avaliados agora pelo governo. (REPÓRTER BRASIL, 2020, p.2).
\end{abstract}

Para entender esse acentuado uso de agrotóxicos na produção de alimentos no Brasil, Pignati et al. (2017) elencam uma série de fatores que contribuíram para o aumento do consumo de defensivos agrícolas. Os autores justificam que o status mundial de maior consumidor de agrotóxicos é em decorrência da extensa área de plantio brasileira. Além do mais, a exigência da política de apoio aos pacotes tecnológicos da Revolução Verde, a produção de alimentos transgênicos, o aumento de pragas nas lavouras, os financiamentos agrícolas e a isenção de tributos fiscais, tem contribuído para o elevado consumo (PIGNATI et al., 2017).

Aumento este que se cresce de forma exponencial ao longo dos anos como se observa na Figura 1, pode-se observar o expressivo aumento entre 2016 e 2020, ano o qual o Brasil registrou o seu maior marco de agrotóxicos sem nenhuma dificuldade imposta pelas instâncias maiores. Segundo dados do jornal O Globo, em 2020 foram liberados 493 pesticidas - 480 genéricos e 13 inéditos, com 4 novos princípios ativos sendo eles: piroxasulfone, tolfenpirade, tiencarbazona e fenpirazamina. 
Figura 1: Registro de Agrotóxicos no Brasil

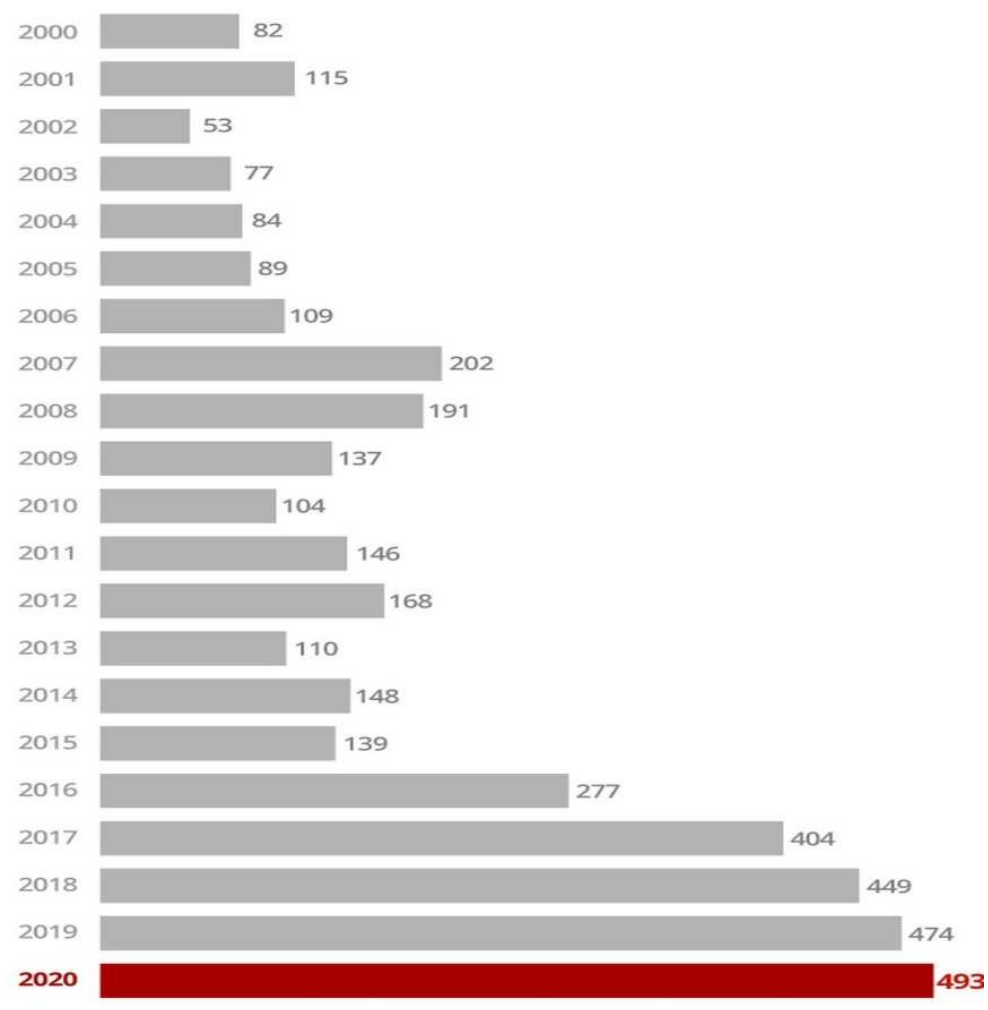

Fonte: Ministério da Agricultura (2021).

Os dados evidenciados na Figura 1 são alarmantes e perturbadores. O elevado uso de agroquímicos podem acarretar danos irreversíveis a saúde humana e ao meio ambiente, concomitante a isso, a intensa crise ambiental advinda do modelo agroexportador que semeia os agrotóxicos nas terras brasileiras. Publicações de instituições internacionais do trabalho (OIT) e da saúde (OMS) apontam estimativas de que em países em desenvolvimento, como o Brasil, "os agrotóxicos causam anualmente 70 mil intoxicações agudas e crônicas que evoluem para óbito, e pelo menos sete milhões de casos de doenças agudas e crônicas não fatais" (CARNEIRO et al., 2015 apud BURIGO, 2016, p.18). Fomentando a discussão, Coelho (2017) aponta em sua pesquisa as seguintes doenças:

O trabalho de Mesnage et al (2017) apresenta evidências que confirmam que a exposição crónica a doses muito baixas de HBG, pode conduzir a disfunção funcional do fígado. [...] diversos estudos mostraram que a exposição ao glifosato se associava a stress oxidativo em regiões específicas do cérebro (como a substância nigra, córtex cerebral e o hipocampo) e a neuroinflamação (Cattani et al 2014) [...] observou-se que a administração de Roundup $(50 \mathrm{mg} / \mathrm{Kg})$, desde o período perinatal até à lactação, não induzia toxicidade materna mas causava problemas reprodutivos na descendência masculina, incluindo alterações na espermatogénese e dos níveis de testosterona em adultos (Dallegrave et al 2007) [...] a carcinogenicidade em humanos foi sustentada por vários estudos epidemiológicos que mostraram uma associação positiva entre a 
exposição ocupacional ao glifosato e subtipos de linfoma não Hodgkin (Schinasi e Leon 2014) [...] estudos epidemiológicos em humanos, têm observado o aumento da ocorrência de malformações congénitas, abortos espontâneos, partos pré-termo e defeitos do tubo-neural, em regiões onde grandes quantidades de HBG são aplicadas. (COELHO, 2017, p. 23-27).

Quanto ao uso do termo agrotóxico, a saber, de acordo com a Lei Federal, ( $\mathrm{n}^{\mathrm{o}}$ 7.802, Artigo 2, Inciso I), de 11 de julho de 1989 entende-se por agrotóxico:

\begin{abstract}
Os produtos e os agentes de processos físicos, químicos ou biológicos, destinados ao uso nos setores de produção, no armazenamento e beneficiamento de produtos agrícolas, nas pastagens, na proteção de florestas, nativas ou implantadas, e de outros ecossistemas e também de ambientes urbanos, hídricos e industriais, cuja finalidade seja alterar a composição da flora ou da fauna, a fim de preservá-las da ação danosa de seres vivos considerados nocivos. (BRASIL, 1989, p.1).
\end{abstract}

Em virtude do uso indiscriminado dos defensivos agrícolas, o INCA (2015) chama a atenção em seu relatório quanto ao consumo de agrotóxicos. Segundo o relatório, o cultivo através do uso violento de agrotóxico, gera grandes nocividades ao meio ambiente e a saúde da população. A exposição aos agrotóxicos acarreta desde a intoxicação aguda, (irritação nos órgãos do corpo, vômitos e até mesmo a morte), subaguda (má formação fetal), até a um contato indireto, a crônica, isto é, o indivíduo não tem contato com o ambiente de maior presença dos produtos químicos, mas, os resíduos de agrotóxicos encontrados nos alimentos mesmo que em pequena quantidade, ao longo do tempo pode fazer surgir a manifestação de doenças graves como o câncer (PIGNATI et al., 2017).

É preciso evidenciar que estes resíduos químicos, não estão presentes apenas nos alimentos em seu estado natural, ou seja, aqueles que não passaram por nenhum processamento. Nesse sentido, o Instituto Nacional de Câncer (INCA) destaca que:

[...] muitos produtos alimentícios processados pela indústria, como biscoitos, salgadinhos, pães, cereais matinais, lasanhas, pizzas e outros que têm como ingredientes o trigo, o milho e a soja, por exemplo. Ainda podem estar presentes nas carnes e leites de animais que se alimentam de ração com traços de agrotóxicos, devido ao processo de bioacumulação. Portanto, a preocupação com os agrotóxicos não pode significar a redução do consumo de frutas, legumes e verduras, que são alimentos fundamentais em uma alimentação saudável e de grande importância na prevenção do câncer. (INCA, 2015, p.3).

Consequentemente, mitigar o impacto do uso dos defensivos agrícolas é a melhor forma de combater não só os problemas de saúde ocasionados pelo seu uso, como ainda 
preservar os recursos naturais indispensáveis como o solo, à água a fauna e a flora. Assim, a agricultura orgânica se apresenta como alternativa para este modelo de produção, que tanto mata ao longo de anos. Burigo (2016) ensina que, segundo estudos realizados pela Universidade Estadual de Washington (EUA), pesquisadores de diferentes nacionalidades: "mostraram que a agricultura orgânica pode ser usada para alimentar de maneira eficiente toda a população mundial, com rendimentos suficientes para os produtores [...]” (BURIGO, 2016, p.8).

Nessa conjuntura, a Educação Socioambiental, que tem sua base teórica na Educação Ambiental, acrescentando assim a questão antrópica a ambiental, passa a exercer ações éticas, políticas e científicas, que tem papel fundamental na formação e promoção da conscientização ambiental dentro da sociedade, levando a população a aprender e refletir sobre as ações e práticas socioambientais a serem desenvolvidas dentro da comunidade. Tratando-se da conceituação de Educação Ambiental, segundo Nana Medina, citado por Fonseca (2009):

[...] o processo que consiste em propiciar às pessoas uma compreensão crítica e global do ambiente, para elucidar valores e desenvolver atitudes, que lhes permitam adotar uma posição consciente e participativa a respeito das questões relacionadas com a conservação e adequada utilização dos recursos naturais, para melhoria da qualidade de vida e a eliminação da pobreza extrema e do consumidor desenfreado. (MEDINA, 1998, p.69 Apud. FONSECA, 2009, p.91).

A Educação Ambiental e a Educação Socioambiental assumem um enfrentamento radical aos problemas encontrados seja no espaço urbano ou rural, além do mais, desperta intrinsecamente a tomada de decisões levando o sujeito a ter um compromisso com a conservação do planeta. A escola torna-se o elo entre o conhecimento cientifico e o comum, entre o rudimentar e o tecnológico e ainda, a formação de cidadãos conscientes.

Sendo assim, a Educação Socioambiental traduz a intrínseca ligação nas ações de ensino e aprendizagem que representam as questões sociais e ambientais, num sistema de duas vias, em que ambas se retroalimentam. Ter em vista a educação ambiental dentro do currículo escolar “tornar-se necessário um planejamento didático-pedagógico” (FONSECA, 2009, p. 94).

Ainda para Fonseca (2009) as diferentes estratégias pedagógicas permitem executar em sala de aula o desenvolvimento de métodos e técnicas de ensino, aptos a atribuir a essa educação ambiental uma natureza multiplicadora do saber. Alinhando as observações realizadas em sala de aula envolvendo a disciplina de Geografia e a temática ambiental, é notório que ainda dentro de alguns espaços escolares o quanto a Educação Socioambiental precisa caminhar 
para um ensino e aprendizagem significativos e ultrapassar os hiatos dos currículos escolares, que a torna fragmentada. De modo geral, apenas a Geografia e a Ciências da Natureza têm exercido a oportunidade de trabalhar com a temática ambiental.

Em suma, trabalhar a questão ambiental é importante quando evidentemente o perigo está em volta do sujeito e do meio ambiente. Segundo (CARNEIRO et al., 2015) Goiás está entre os maiores produtores de monocultura e também é um dos Estados que mais utiliza agrotóxico, alcançando um percentual de $8,8 \%$ do total consumido no país. Aproximando-se de outros grandes consumidores de agrotóxico como Minas Gerais (9,0\%) e Mato Grosso (18,9\%). (CARNEIRO et al., 2015).

Estas estatísticas são significativas do grande problema que está instalado no meio ambiente: poluição, degradação e contaminação de mananciais e dos solos. Soma-se a isso os dados apresentados por Burigo (2016) em que expõe em sua obra a estimativa de que "cada brasileiro ingira uma média de 5,2 litros de venenos por ano, o equivalente a duas garrafas e meia de refrigerante, ou a 14 latas de cerveja" (BURIGO, 2016, p.3). Ao serem apresentadas essas informações os alunos mostraram-se surpresos com o tamanho da problemática que a humanidade enfrenta sobre o veneno que está sobre à mesa de cada um, aparentemente invisível, impactando a saúde dos brasileiros.

\section{ROTAS E PROCEDIMENTOS METODOLÓGICOS}

As atribuições metodológicas serão tratadas em dois âmbitos: primeiro, o itinerário dos procedimentos e técnicas de pesquisas para a elaboração do artigo; e, em segundo lugar, serão descritas as trilhas para planejamento e preparação das aulas. A importância da segunda 'etapa metodológica' é que essa impacta os resultados do artigo e ajuda a definir o destino daquilo que se investigou/experienciou, que enfim, se consubstancia nesse trabalho.

A rota para a escrita desse artigo passou pela revisão bibliográfica selecionada para abordagem e discussão das categorias principais desse trabalho, que são as seguintes: Educação Socioambiental, Educação Agroecológica, Resíduos Sólidos Domésticos e Agrotóxicos. Dada a pertinência dos temas e sua inserção nas Unidades Temáticas (UT) e objetos de ensino na Base Nacional Comum Curricular (BNCC) do Ensino Fundamental.

A proximidade dos estudantes/estagiários de Licenciatura em Geografia com o Núcleo de Estudos, Pesquisas e Extensão em Agroecologia (NEPEA) proporcionou breves debates 
sobre os temas/UT e direcionou o foco das leituras e revisões de bibliografias sobre tais categorias. Essa etapa dos procedimentos instrumentalizou-os para os planejamentos, preparações de aulas e oficinas e para ministrarem os conteúdos estudados e compreendidos para serem expostos/explicados/ministrados nas aulas dos sextos e sétimos anos do EF.

A etapa e itinerários da inserção participante na Escola ocorreu a partir da observação do processo educativo e a posterior intervenção planejada. Os assuntos como separação de resíduos, noções e conceitos sobre Agroecologia e técnicas de compostagem, à questionários e ferramentas lúdicas (Quiz Agroecológico), foram desenvolvidos por meio do diálogo, conscientização e da mediação significativa para com os escolares, onde embasados nestes meios de abordagem, pudessem internalizar tanto os conceitos, quanto conciliar suas práticas cotidianas de alimentação e consciência ecológica e sustentável, estabelecendo um paralelo sobre seus hábitos.

O trabalho com as categorias transformadas em objetos de ensino se deu por meio de aulas, oficinas e atividades lúdicas, que expunham, discutiam e desvelavam saberes e conhecimentos de Educação Socioambiental na Escola Estadual Instituto de Educação Matilde Margon Vaz na cidade de Catalão (GO) como se observa na Figura 2. 
Figura 2 - Localização do Instituto de Educação Matilde Margon Vaz
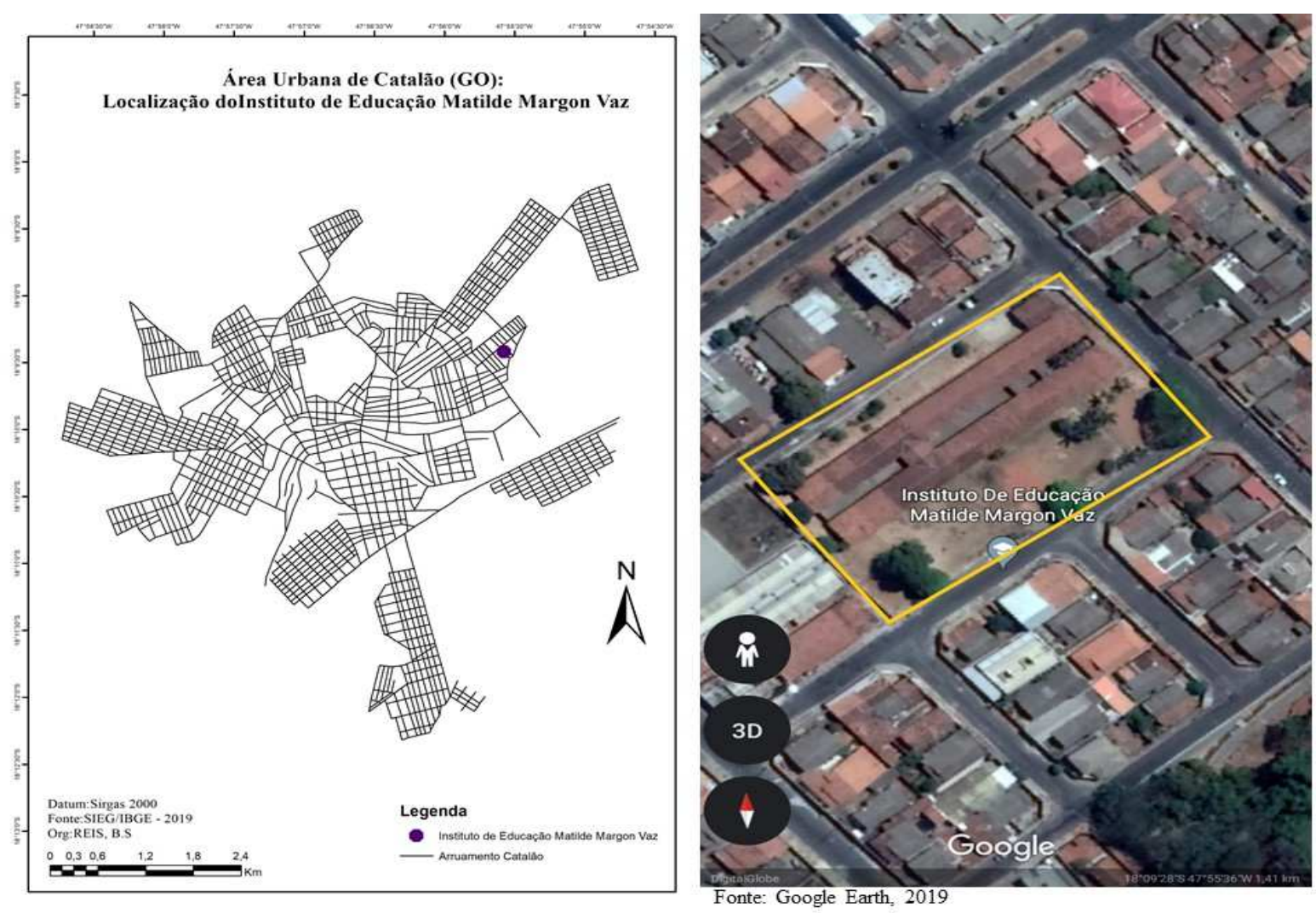

Fonte: Santos, L.K., 2019.

O Instituto de Educação Matilde Margon Vaz) está situado na cidade de Catalão no Endereço: R. Vinte e Um, 135 - St. Universitário, CEP: 75706-310. Inserido nas coordenadas geográficas: Latitude: $18^{\circ}$ 9'27.98"S e Longitude: 4755'36.39"O. A escola faz limites com a quadra de esportes do Setor Universitário (utilizada pela escola para aulas de educação física), com a Creche Cleonice Evangelista do Nascimento, da rede municipal de ensino e com a reserva florestal (matinha do Setor Universitário). Ficando próxima também, a Universidade Federal de Catalão, com a qual estabelece parcerias como os Estágios referentes aos cursos de Licenciaturas, e com Programas como o PIBID, facilitando assim o acesso aos laboratórios e espaços da regional para aulas diferenciadas. 


\section{RESULTADOS E DISCUSSÃO}

Por meio das intervenções mencionadas anteriormente, os resultados foram coletados e dispostos no artigo a fim de demonstrar a necessidade de se estruturar o ensino de Educação Socioambiental e Agroecológica nas escolas do EF. As aulas foram gestadas como proposta para um ensino sustentável, tendo por base a Educação Socioambiental e a Agroecologia.

Os participantes, que operacionalizaram a proposta de intervenção, entendem a necessidade e a urgência da Educação Socioambiental nas escolas, visto que não apenas o cenário brasileiro, porém, também o mundial, encontram-se cada vez mais envolvidos em uma teia de degradação ambiental. Fazer uma mediação didática agroecológica se torna indispensável, pois a conscientização tende abarcar todo corpo escolar, e incentivar práticas sustentáveis desde as mais corriqueiras como a separação de resíduos, quanto as mais emergentes como tomar-se ciência dos agentes químicos que se apresentam na alimentação diária das crianças brasileiras, e como sugere Bertazzo (2016) “ a experiência com extensão e pesquisas em Agroecologia viabiliza a matriz para intervenções docentes nos contextos escolares" (BERTAZZO, 2016, p.12).

Dentro dos contextos dos alunos que frequentam os sextos e sétimos anos da escola em que se desenvolveu o processo, muitos ainda têm fortes ligações com o mundo rural, por meio de seus familiares.

Ressalta-se que as atividades agropecuárias tem grande força e relevância em Catalão e região, como grande parte do Sudeste Goiano. Assim, consequentemente, é recorrente o conhecimento e a difusão do uso intensivo de defensivos agrícolas. A grande maioria das famílias acaba por adquirir e consumir em suas refeições produtos com esses agentes químicos, e até mesmo na escola, que por pouca verba busca por alimentos mais baratos, para fazer multiplicar a merenda, muitas vezes não conhecendo a procedência dos alimentos.

Por esses motivos, e pela ausência de diálogos e debates nos livros didáticos acerca da necessária e inteligente preservação ambiental e do uso racional e equilibrado dos bens naturais, elenca-se que as agriculturas possam ser técnicas, precisas e menos predadoras do meio natural de seus entornos. Dentro disso, e já desde muito tempo, as comunidades se ressentem da ausência de clareza e transparência sobre os efeitos colaterais e sobre a nocividade dos agrotóxicos com toda a população e com os escolares do EF. 
Então, ao se compreender que essas intervenções eram incontornáveis e necessárias, partiu-se para a instrumentação de conhecimento e para elaboração de um programa de formação que fosse capaz de despertar o debate e a reflexão, por parte dos escolares participantes, e proporcionar a tomada de consciência acera dos meios de produção alimentos nas agriculturas praticadas no Brasil, bem como seus principais efeitos na saúde humana, animal e na biodiversidade em geral. Pois, como percebe Bertazzo (2016): "ensinar Agroecologia ou Educação Socioambiental, mais do que exercer uma militância, possibilita criar competências para um quefazer agrícola em bases conservacionistas que aponta para o bem viver" (BERTAZZO, 2016, p.11).

Isto posto, a intervenção dos estagiários, apoiados teoricamente pelo NEPEA, na escola visou além de ressaltar a relevância da consciência ambiental, fazer os alunos refletirem sobre o que consomem e se é possível adotar modelos sustentáveis começando a mudança nas suas próprias casas e na escola, respondendo as seguintes perguntas: a alimentação saudável é direitos de todos? Podemos começar com pequenas mudanças em nossa própria casa fazendo uso de técnicas agroecológicas? Posso ser saudável sem gastar muito?

Essas abordagens buscavam, por meio de diálogos socráticos, desenvolver a curiosidade e o desejo de aprender daqueles alunos do sexto e do sétimo ano do EF. Pois, como adverte Moran (2012):

Não basta colocar os alunos na escola. Temos que oferecer-lhes uma educação
instigadora, estimulante, provocativa, dinâmica, ativa desde o começo e em todos os
níveis de ensino. Milhões de alunos estão submetidos a modelos engessados,
padronizados, repetitivos, monótonos, previsíveis, asfixiantes. (MORAN, 2012, p. 8).

Concordando com as ideias desse autor, prosseguiu-se com o trabalho nas turmas. A escola, então aderiu à proposta, e permitiu que a bolsista que também é estagiária do curso de Geografia juntamente com seu colega, começasse as intervenções durante os Estágios Supervisionados II, III e IV em Geografia. Haja vista, que para realização do Estágio se faz necessário aulas de Geografia. A Agroecologia se abriga nas aulas de Geografia e proporciona aos alunos conhecimentos críticos sobre sociedade, saúde e educação e desenvolvimento da consciência ambiental.

Com essas práticas, iniciaram-se as intervenções nas turmas dos $6^{\circ}$ ano "A" e "B" e do $7^{\circ}$ ano "A" e "B" da escola. Trazendo como pressuposto principal, o cotidiano do aluno para 
significação das aulas, pois a partir de questionamentos sobre alimentação e práticas ambientais deles, se começava as interações.

Nas primeiras aulas discutiu-se sobre a separação de resíduos domésticos, explicando o descarte correto e como se poderia colaborar para harmonia do meio ambiente, iniciando as primeiras noções de consciência ambiental com aulas expositivas e dialogadas, intensificando o uso dos diálogos socráticos, por meio dos quais os alunos iam desenvolvendo seus raciocínios e aprofundando as questões que eram propostas pelos ministrantes e entre eles mesmos. Assim, os alunos relatavam como era separação de resíduos em suas casas, exemplificando casos do cotidiano, bem como, poderiam contribuir para diminuição de lixo depositado na natureza. Sobre diálogos socráticos, Ferreira e Silva apontam:

O método de Sócrates de busca do conhecimento, a dialética socrática pode ser
dividida em três momentos1: a) ironia (exortação); b) refutação; c) maiêutica. A ironia
assume uma característica formal e também substancial no método socrático. Ela viria
a ser o ponto de partida para colocar em prática a metodologia socrática. A ironia seria
o jogo brincalhão, múltiplo e variado das ficções e dos estratagemas realizados por
Sócrates para levar o interlocutor a dar conta de si mesmo. 1 A refutação teria a função
de despertar nos outros a consciência de sua ignorância, ou seja, orientar os caminhos
para uma purificação espiritual dos erros e faltas. Ela encaminha o espírito para a
descoberta da verdade: Somente o espírito purificado e libertado. A terceira etapa do
método socrático é realizada pela Maiêutica ou a arte do parto (do grego, maieutiké).
Em virtude de sua importância capital no método socrático, muitas vezes refere-se a
ele apenas como Maiêutica. Trata-se de uma reflexão investigante, ou seja, estimula
a especulação em vez de oferecer a doutrina. Acredita-se que o interrogado extraia
suas respostas e descobertas do interior do seu espírito. (FERREIRA E SILVA, 2004,
p. 36-37).

Em contrapartida foi feito uso de atividades lúdicas para fomentar a medição e a construção do conhecimento, por meio de brincadeiras. A escola no momento das intervenções não possuía recipientes da coleta seletiva, havia uma promessa de doação desse material, mas naquele momento, o único recipiente que a escola obtinha era uma espécie de vasilhame de borracha, onde os resíduos eram jogados sem separação. Então buscou-se este exemplo, da própria escola para explanar sobre os meios corretos de descarte, para figurar como depositar de forma certa utilizamos o um jogo de questionamentos (conforme Figura 3), nesta brincadeira havia vários tipos de perguntas sobre os diferentes tipos de resíduos. 
Figura 3: Atividade Lúdica - Coleta Seletiva

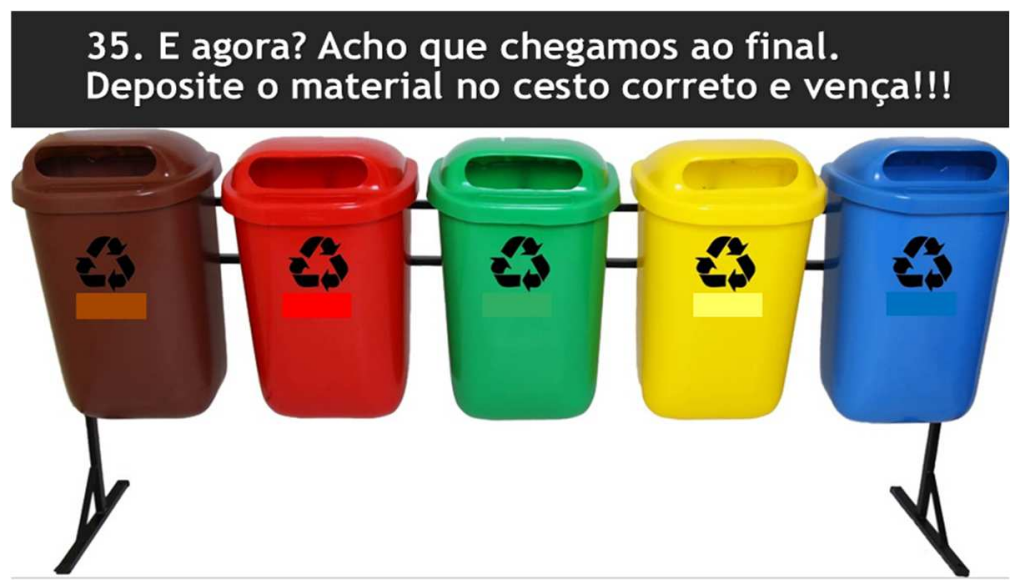

Fonte: Santos, L.K., 2019.

As turmas eram separadas em dois grandes grupos, e se esforçaram ao máximo para responder de forma correta os questionamentos da brincadeira, todos foram participativos, se mostrando surpresos antes das explanações, pois, muitos não sabiam que havia uma coleta especifica para cada tipo de material, nem tão pouco, os riscos ambientais e a saúde que o material contaminado pode causar. A escolha da atividade lúdica, foi um meio para instigar os alunos pois entendemos que brincar é um dos melhores métodos para a construção da aprendizagem e como elucida Almeida (1995) "a educação lúdica é uma ação inerente na criança e aparece sempre como uma forma transacional em direção a algum conhecimento, que se redefine na elaboração constante do pensamento individual em permutações constantes com o pensamento coletivo" (ALMEIDA, 1995, p.11). Jiménez e Gaite complementam:

\begin{abstract}
Jogos de simulação são para a Geografia, e as ciências sociais em geral, como as experiências de laboratório para as ciências experimentais. O Geógrafo não consegue reproduzir no laboratório os fatos e fenômenos que estuda, reproduz recorrendo à simulação e ao jogo. Isto permite abordar com simplicidade certos temas de caráter complexo [...] sendo adequadas ao processo de ensino aprendizagem. (JIMÉNEZ E GAITE, 1995, p. 83).
\end{abstract}

Nas aulas posteriores foram introduzidas as noções agroecológicas, partindo de questionamentos como: vocês sabem o que a Agroecologia? O que é a compostagem? Quanto cada brasileiro consome em média de veneno anualmente? O que é agricultura familiar e produção orgânica? Esperávamos as reações e as repostas dos alunos que eram as mais diversas, e assim, paulatinamente eram feitas as explanações. No $7^{\circ}$ ano "A" e "B", o conceito de Agroecologia se apresentou como algo novo, pois a maioria ainda não tinha ouvido falar da 
temática, alguns respondiam que era algo que se relacionava com agricultura, chegando um aluno até mesmo a questionar: "é aquilo que passa na tv... o agro é pop?"

Diante disso, evidentemente ressaltou-se a preocupação em elucidar para os alunos o que é a Agroecologia, e a importância da produção orgânica para a alimentação, e qualidade de vida, visto, que a maioria dos alunos, não sabiam ainda a diferença do produto orgânico e o produto com agrotóxico, eles relatavam que sabiam que o veneno é ruim, mas não que causava uma grande quantidade de doenças e malefícios ao corpo humano.

Para complementar a explicação sobre a relação da toxicidade dos defensivos agrícolas e a saúde. Foram expostos vários exemplos e estudos de casos de pessoas que sofreram e sofrem, enfermidades relacionadas a exposição de venenos, inclusive exemplificando casos da própria cidade de Catalão, com literaturas e estatísticas de pesquisas na área. Isto, despertou um interesse de boa parte dos alunos, pois não imaginavam a complexidade da temática, corroboraram com a aula a todo tempo, contribuindo para as discussões e os questionamentos levantados durante a explicação, expondo alguns deles, casos pessoais, relacionando a intoxicação por defensivos agrícolas.

Após várias discussões os alunos começaram a destacar a importância da Agroecologia, porém ainda com algumas dúvidas e com muita atenção procurávamos responder didaticamente a todas as perguntas. Com mais uma atividade lúdica o Quiz Agroecológico conforme (Figuras 4 e 5).

Figura 4: Perguntas do Quiz Agroecológico

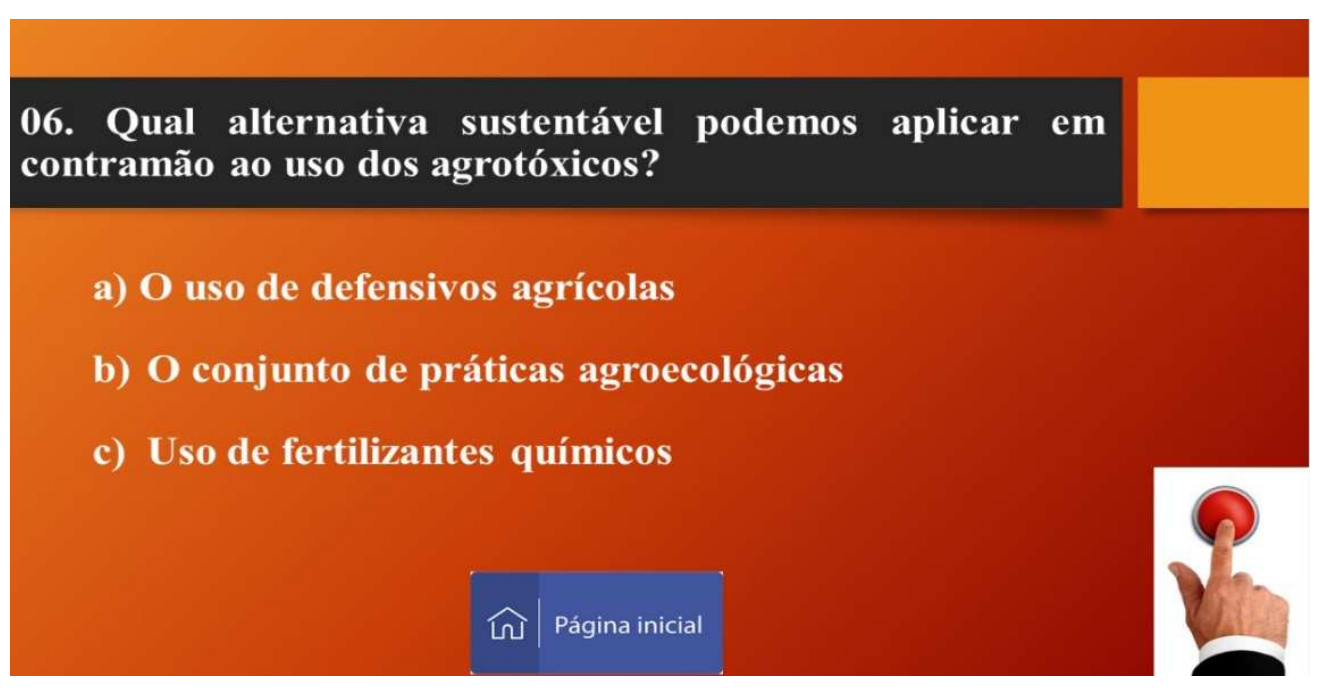

Fonte: Macedo, R. F. de, 2019. 
Figura 5: Aplicação do Quiz Agroecológico

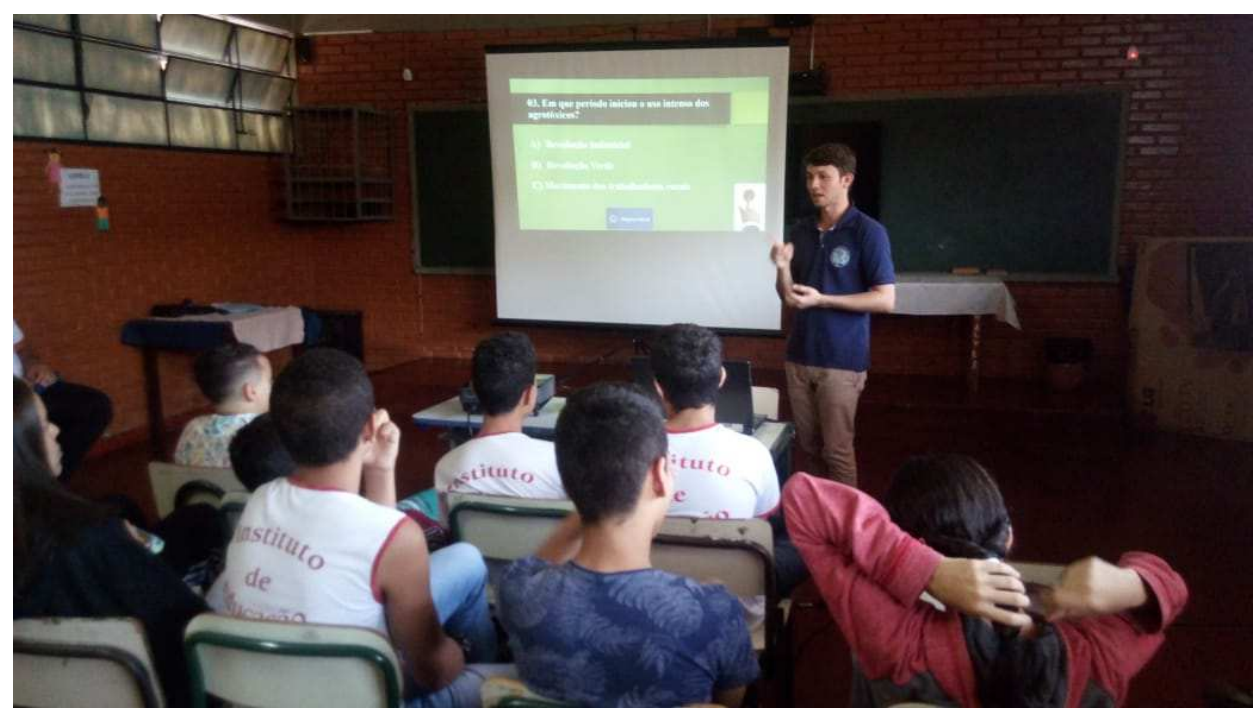

Fonte: Barbosa, G. A. Novembro, 2018.

A dinâmica foi elaborada pelos próprios estagiários, com o programa PowerPoint e a ferramenta Hiperlink, mais um jogo de perguntas e respostas, este com uma interface dinâmica que chamava atenção dos escolares, ao todo eram 12 questões, conforme pode se observar na Figura 6:

Figura 6: Painel do Quiz, Agroecológico

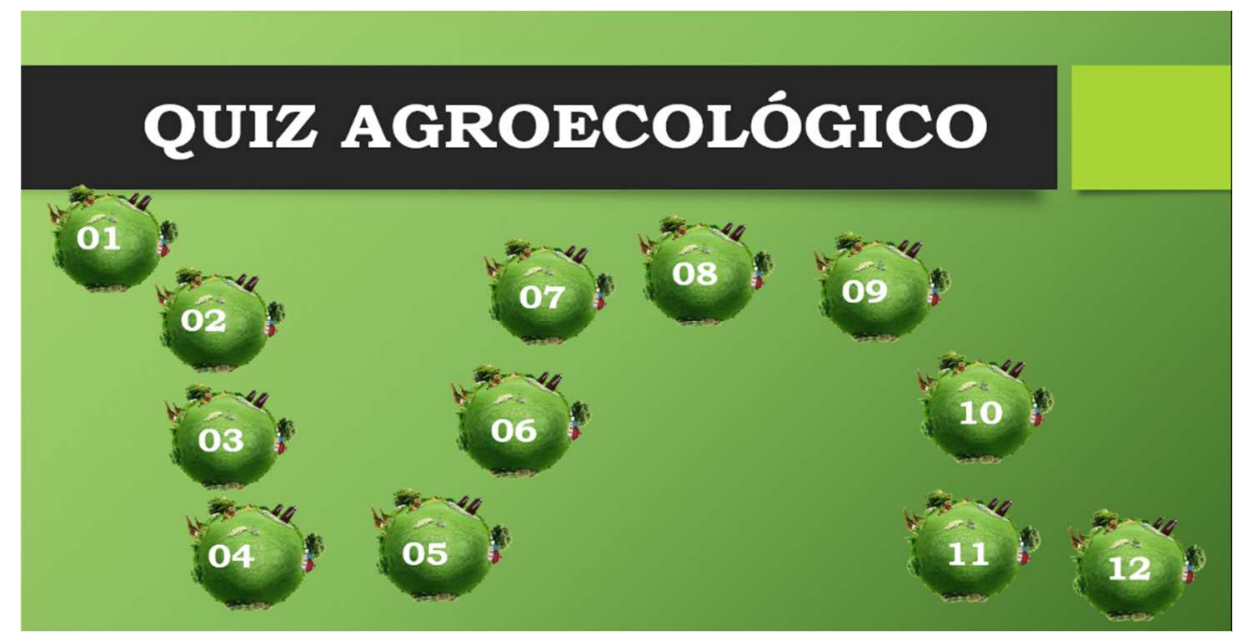

Fonte: Santos, L.K., 2019.

Assim, as turmas novamente foram divididas em dois grupos, os quais escolhiam um participante por rodada, que então selecionava um número na tela, e este continha uma 
pergunta, se o aluno e seu grupo acertassem pontuava para sua equipe. Os alunos se mostraram mais uma vez, participativos e curiosos as aulas e a aplicação das atividades lúdicas, pois como fundamenta Vygotsky (1989), "o lúdico liberta a criança das amarras da realidade" (VYGOTSKY, 1989, p.84). E de forma mais atenciosa possível, buscamos disseminar a importância da Agroecologia para saúde e para o meio ambiente, promulgando técnicas como a compostagem para a produção do próprio adubo orgânico.

Buscou-se reforçar a todo momento a relevância das técnicas agroecológicas em relação a sociedade e o meio ambiente, abriu-se mais um espaço para questionamentos e depoimentos dos alunos depois da finalização dos jogos e atividades, pois, notadamente alguns ainda se mostraram confusos e intrigados com a temática, e destacaram sua surpresa quanto aos efeitos nocivos dos agrotóxicos. Para finalizar a atividade foi distribuído um questionário com perguntas sobre o que foi discutido ao longo das aulas (Quadro 1), para as duas turmas somando o total de 42 alunos que se dispuseram a responder.

\section{Quadro 1: Enquete}

\section{Na sua casa você e seus pais utilizam produtos orgânicos ou não?}

(10 alunos) sim; (32 alunos) não.

\section{Você sabia da nocividade de consumir produtos com agrotóxicos?}

(16 alunos) sim; (9 alunos) não;

(17alunos) parcialmente.

A partir de agora você pretende começar a consumir com frequência produtos agroecológicos?

(10 alunos) já consumo; (6 alunos) não pretendo consumir; (26 alunos) quero começar.

Na sua casa você e seus pais fazem compostagem?

(5 alunos) sim; (37 alunos) não.

Você conhece algum caso de intoxicação por agrotóxicos?

(14 alunos) sim; (28 alunos) não.

\section{Para você ficou claro o significado da Agroecologia?}

(39 alunos) sim; (3 alunos) não.

Fonte: Santos, L. K., 2019.

Com o quadro acima fica evidente que a Educação Socioambiental, se faz mais que emergente no Ensino Básico, primeiro pelo desconhecimento da diferença do produto orgânico, 
e um com defensivo. Segundo, pelo fato dos 42 alunos que foram indagados sobre a nocividade dos agrotóxicos, apenas 16 responderam que sim, isto é, $38 \%$ dos alunos apenas. Terceiro, apenas 10 informaram que já consomem produtos orgânicos, e 6 alegam que não pretendem consumir, acreditamos que devido ao valor dos produtos ou má informação dos responsáveis pelas crianças. Apenas 5 praticam a técnica da compostagem e 4 deles moram na zona rural, apenas 1 na zona urbana. E por fim, apesar da maioria não consumir produtos orgânicos e/ou não ter um conhecimento mais concreto sobre os defensivos agrícolas, uma boa parte conhece casos de intoxicação. E a partir das aulas, passaram a ter conhecimento de toda a nocividade desses produtos e da importância de preservar o meio ambiente.

Durante as aulas dois casos específicos chamaram atenção, quando questionados se eles sabiam o nome de alguns tipos de venenos mais utilizados na agricultura brasileira, primeiro no 7 "A" um aluno falou Roundup ${ }^{1}$ e no 7 "B", ocorreu a mesma coisa, ambos alunos moram na zona rural de Catalão. O primeiro informou que a tia se suicidou com o produto, inclusive foi um dos poucos alunos que respondeu de forma correta as perguntas sobre as técnicas agroecológicas, e afirmou que na sua roça era praticada a agricultura familiar.

O segundo caso, foi ainda mais assustador, pois a criança alegou que já tinha se intoxicado várias vezes com o defensivo, e sentia enjoos e fortes dores de cabeça, isto porque, o pai dele fazia pequenos cultivos de grãos e hortaliças e utiliza o produto, com ajuda da criança. Então, foi reforçado mais uma vez o perigo da exposição não só ao glifosato mais aos demais tipos de pesticidas, herbicidas e fungicidas. Foram poucos os alunos que informaram que consumiam produtos orgânicos, em pouco mais de 40 alunos apenas 10 afirmaram que consumiam tais produtos, um deles porque a avó teve leucemia, e desde então passou a consumir produtos com selo orgânico, outros porque os pais ou avós moravam na zonal rural e produziam frutas e hortaliça segundo eles, sem agrotóxicos.

\section{CONSIDERAÇÕES FINAIS}

Dentre os objetivos educacionais, de ensino e aqueles que moveram à redação desse artigo, a pesquisa atendeu ao que foi proposto. Pois, considerando que a pesquisa bibliográfica permitiu aos estagiários/ministrantes compreender mais profundamente os conceitos das

\footnotetext{
${ }^{1}$ Produto patenteado pela empresa Monsanto/Bayer.
} 
categorias chaves que sustentam a presente proposta, e permitiu-lhes construir o presente artigo e também proporcionou conhecimentos didáticos dos conteúdos que foram apresentados criticamente nas aulas. As ordens de objetivos se realizaram nas aulas e no texto ora finalizado.

Considera-se que houve um aumento no repertório de conhecimentos e internalização dos conceitos sobre questões socioambientais, agroecológicas, resíduos sólidos e agrotóxicos por todos os alunos participantes dos eventos formativos que se preparou e ministrou nos sextos e sétimos anos. A proposta de intervenção dos estagiários, apoiadas pelo Núcleo de Estudos, Pesquisas e Extensão em Agroecologia (NEPEA), logrou êxito em sua intenção de promover a conscientização das mais críticas situações Socioambientais e Agroecológicas. Tais exposições/demonstrações e debates proporcionaram aos escolares a reflexão e formação de competências e habilidades para a tomada de decisões sobre tais questões. De modo que se envolveram no processo de sua própria formação integral, na qual a cidadania é uma importante componente.

A Escola parceira também esteve, inicialmente, como solicitante de uma iniciativa com uma temática que envolvesse os jovens, com o objetivo de discutir formas mais sustentáveis de se plantar, preservar e consumir. Depois de encerrada essas atividades relatadas anteriormente, foi preparada uma outra iniciativa que pudesse abraçar mais professores e alunos para as questões socioambientais, agroecológicas e de cultivos sem agrotóxicos. Isso mais do que um resultado, foi uma clareira que se abriu na escola pública para se realizar hortas demonstrativas, consolidando conceitos socioambientais e de práticas agrícolas não predatórias e contaminantes com pesticidas e plantas espontâneas/invasoras.

Finalmente, as metas mais simples contidas numa proposta de intervenção e formação no ensino fundamental, transformaram-se numa contundente ferramenta para debater, expor, ensinar e aprender conceitos e técnicas, como por exemplo: sustentabilidade ambiental, cultivos sem agrotóxicos, preservação ambiental, segregação de resíduos sólidos, reciclagens e Agroecologia. Então, tornaram-se importantes valores éticos e socioambientais para a formação integral daqueles alunos dos sextos e sétimos anos. Isso destaca a Geografia como disciplina escolar que promove o pensamento crítico, holístico do alunado, bem como a compreensão do direito â cidadania. 


\section{REFERÊNCIAS}

ALMEIDA, P.N. Educação lúdica: técnicas e jogos pedagógicos. São Paulo, SP: Loyla, 1995.

BERTAZZO, C. J. Agroecologizando no cerrado. 1. ed. CATALAO: NEPEA/Retratando o Cerrado, 2016.

BRASIL. Lei Federal $\mathbf{n}^{\mathbf{0}} \mathbf{7 . 8 0 2}$ de 11/07/1989. Dispõe sobre os agrotóxicos. Disponível em: <http://www.planalto.gov.br/ccivil_03/LEIS/L7802.htm>. Acesso em: 23 de nov. 2018.

BRASIL. Base Nacional Comum Curricular - BNCC. Documento homologado pela Portaria n 1.570, publicada no D.O.U. de 21/12/2017, Seção 1, Pág. 146, 2017.

BURIGO, André. Impacto dos Agrotóxicos na alimentação, saúde e meio ambiente. 2016. Disponível em:< http://www.mobilizadores.Fontebr/wp-content/uploads/2016/08/CartilhaAgrotoxicos-final.pdf > Acesso em: 12 de nov.2018.

CARNEIRO, F. F.; AUGUSTO, L. G. da S.; RIGOTTO, R. M.; FRIEDRICH, K.; BÚRIGO, A. C. (Fonte). Dossiê ABRASCO: um alerta sobre os impactos dos agrotóxicos na saúde. Rio de Janeiro: Escola Politécnica de Saúde João Venâncio: São Paulo: Expressão Popular, 2015.

COELHO, M. C. R. S. Glifosato, Saúde e Ambiente - uma revisão. 2017. Dissertação de Mestrado- Instituto de Ciências Biomédicas Abel Salazar - Universidade do Porto, 2017. Disponível em:< http://hdl.handle.net/10216/110203> . Acesso em 19 jan. 2020.

CASTROGIOVANNI, A. C. et al. Geografia em sala de aula: práticas e reflexões. 2. ed. Porto Alegre: UFRGS/AGB, 1999.

CAVALCANTI, L.S. de. A geografia escolar e a cidade: ensaios sobre o ensino de geografia para a vida urbana cotidiana. Campinas: Papirus, 2008.

FERREIRA, R. A. S.; SILVA, F. W. O. da. Aplicação da maiêutica em atividades formativas de introdução à engenharia. Educação \& Tecnologia. Belo Horizonte, v. 9, n. 1, p. 35 - 41, fev. 2004.

FONSECA, V. M. da. A educação ambiental na escola pública: entrelaçando saberes, unificando conteúdos. $1^{a}$ ed. São Paulo: Biblioteca 24horas, 2009.

IEA - INSTITUTO DE ECONOMIA AGRÍCOLA - IEA. Defensivos Agrícolas: comercialização recorde em 2011 e expectativas de acréscimo nas vendas em 2012. São Paulo: IEA, 2012.

INCA. INSTITUTO NACIONAL DE CÂNCER JOSÉ ALENCAR GOMES DA SILVA. Posicionamento do Instituto Nacional de Câncer José Alencar Gomes da Silva Acerca dos Agrotóxicos. 2015. 
<http://www1.inca.gov.br/inca/Arquivos/comunicacao/posicionamento_do_inca_sobre_os_ag rotoxicos_06_abr_15.pdf>. Acesso em: 23 nov. 2018.

JIMENEZ, A.; GAITE, M. de J. Enseñar Geografia: de la teoria a la práctica. Colección Espacios y Sociedades. Madri: Editorial Síntesis, S.A., 1995.

MORAN, J. M. A educação que desejamos: Novos desafios e como chegar lá. $5^{a}$ ed. Campinas, SP: Papirus, 2012.

Número de agrotóxicos registrados em 2020 é o mais alto da série histórica; maioria é genérico, diz governo. $O$ Globo. 14 de janeiro de 2021.Disponível: < https://g1.globo.com/economia/agronegocios/noticia/2021/01/14/numero-de-agrotoxicosregistrados-em-2020-e-o-mais-alto-da-serie-historica-maioria-e-produto-generico.ghtml> Acesso em 13 de maio de 2021.

Liberação é 'serviço essencial'. Disponível em: <https://reporterbrasil.Fontebr/2020/05/96agrotoxicos-sao-aprovados-durante-a-pandemia-liberacao-e-servico-essencial/ >. Acesso em: 04 jan. 2021.

PIGNATI, W. A. et al. Distribuição espacial do uso de agrotóxicos no Brasil: uma ferramenta para a Vigilância em Saúde. Ciência \& Saúde Coletiva [online]. Rio de Janeiro, v. 22, n. 10, p. 3281-3293, out. 2017.

VYGOTSKY, L. S. A Formação Social da Mente. São Paulo: Martins Fontes, 1989. 